\title{
PRIMARY OSTEOARTHRITIS, VENOUSIENGORGEMENT AND OSTEOGENESIS
}

\author{
M. Brookes and B. Helal, London, England \\ From the Department of Anatomy, Guy's Hospital Medical School, London, \\ and the Enfield Group of Hospitals, London
}

An abnormality in joint mechanics, whatever its origin, is generally considered to be a major factor in the development of osteoarthritis. Nevertheless, in the primary form of this disorder it is notoriously difficult in the individual case to define anatomically the nature of the mechanical disturbance which may have initiated the disease process. On the other hand, the possibility that an abnormality in the osseous circulation may be present has for some years received increasing attention. For example, Harrison, Schajowicz and Trueta (1953) claimed that arterial hyperaemia was characteristic of the bone sclerosis which they studied in coxarthrosis. Their findings were linked, however, with the unsubstantiated proposition that the human hip joint is mechanically imperfect because of man's assumption of bipedalism by descent from a quadrupedal ancestor (Trueta 1954). Recently several investigators have brought forward evidence which implicated defective venous drainage as the sort of vascular disorder which is generally present in osteoarthritis. Intraosseous phlebography of lower limb bones involved in osteoarthritic disease reveals venous dilations in cancellous bone (Helal 1962, Wardle 1964). Delayed emptying of radiopaque media injected into cancellous bone of osteoarthritic joints has been demonstrated by radiocinematography by Pistolesi (1962). Helal (1965) also found that there was a raised incidence of venous varicosities in limbs affected by primary osteoarthritis.

Certain basic assumptions in our approach to the problem are worth emphasising at this point. We consider that in osteoarthritis there is a disturbance of osteogenesis. Furthermore, vascular factors are involved in the mechanism of local control of normal bone turnover. We may also postulate that any aberration in the local vascular conditions within bones will result in a disturbance of osteogenesis, which if sustained will express itself as disease.

The aim of this paper is to present further evidence, both clinical and experimental, which may help to elucidate the role of the blood vascular system in the production of excess bone in osteoarthritis. Nevertheless, the manner in which the blood supply of bone is related to the control of osteogenesis is a keystone to this discussion. Therefore evidence gained from other osteogenic situations-for example, normal bone growth or new bone formation in fracture repair, because they are highly relevant-will be presented also.

\section{CLINICAL INTRAOSSEOUS PHLEBOGRAPHY IN PRIMARY OSTEOARTHRITIS}

\section{MATERIALS AND METHODS}

The radiopaque material used was Hypaque ( 45 per cent). Usually a volume of 5 millilitres was adequate to display the pattern of medullary veins, sinusoids and adjacent deep veins. Amounts of up to $\mathbf{4 0}$ millilitres have been injected in the course of investigation of a number of joints in one patient without ill effect.

To guard against sensitivity reactions an iodine patch test was done, and if it was negative 1 millilitre of 45 per cent Hypaque was given intravenously six hours before venography. The intraosseous investigation was carried out in the operation theatre with full aseptic precautions 
under general anaesthesia or local analgesia. A 20 degrees foot down tilt was found to be the best position. A special needle was designed to facilitate the investigation (Helal 1965). It is of wide bore and has a self-tapping thread which can be screwed through the cortex of the bone within two or three centimetres of the joint to be investigated. After confirmation that there was a free flow of medullary blood, the Hypaque was injected.

So far the procedure has been carried out on bones around the knee, hip, and elbow joints in 190 patients whenever there was a normal control side for comparison. Two patients had Paget's disease of the tibia, and two had rheumatoid arthritis of the knee. The remaining 186 patients were suffering from primary osteoarthritis. In six of these cases the disease was in the elbow joint; twenty-two cases concerned the hip joint and the remaining 158 involved the knee joint.

\section{RESULTS}

The results of clinical investigation of the venous circulation in a large number of bones affected by primary osteoarthritis and other disorders showed the following principal features.

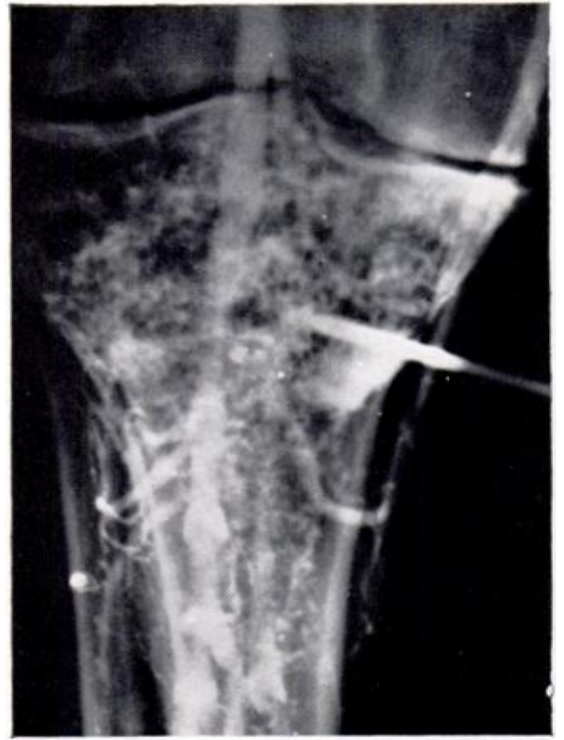

Fig. 1

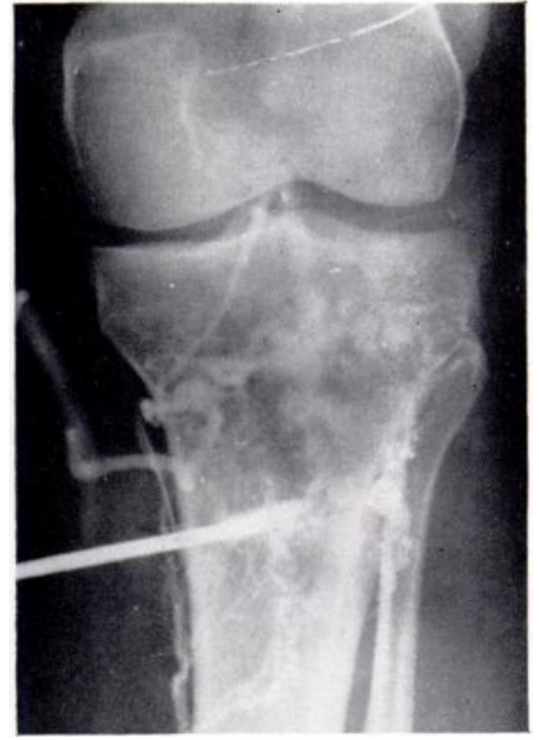

FiG. 2

Figure 1-Phlebograph of upper end of tibia in a case of primary osteoarthritis of the knee. Profuse sinusoid filling is evident and the subchondral vessels are well displayed. The deep veins are also engorged. Figure 2-Phlebographic appearances in the normal joint, the side opposite to that shown in Figure 1. Subchondral vascular engorgement is absent.

Subchondral medullary sinusoids were distended only in those 186 patients with primary osteoarthritis (Figs. 1 and 2) and in one case where Paget's disease abutted against a joint space. The cancellous tissues were not affected by Paget's disease in the other case examined, and here the opaque fluid failed to accumulate in a subchondral position. In primary osteoarthritis the fluid cleared more slowly from the affected side, strongly suggesting a sluggish cancellous circulation. These patients with sinusoidal engorgement all had a history of diffuse aching pain. The affected bone was of softer consistency than normal as judged by the ease of insertion of the needle for intraosseous venography. In eight patients examined after intertrochanteric osteotomy of the femur for osteoarthritis of the hip, and in fourteen patients examined after tibio-fibular osteotomy for osteoarthritis of the knee, relief of pain after the osteotomy was shown to be concurrent with a return to normal size of the distended subchondral vessels. 


\section{EXPERIMENTAL VENOUS CONGESTION OF THE KNEE JOINT}

\section{MATERIALS AND METHODS}

Twenty-four rats each weighing about 250 grammes were anaesthetised with ether. Through a single longitudinal incision on the medial aspect of the thigh, centimetre lengths of the femoral and internal iliac veins were excised between ligatures, care being taken to preserve the femoral artery. The other limb served as a control. The limb operated upon took full weight after the ligations, and showed no signs of oedema, ulceration or gangrene up till the time that the rats were killed eight weeks later. Because the effects of the procedure on locomotor function was negligible, it was considered necessary to check whether venous congestion, as shown by a raised red cell content, had actually been produced in the knee joint tissues which were the object of study.

The circulating red cell volume in the epiphysial tissues of the knee joint were measured by injecting red cells chromated with ${ }^{51} \mathrm{Cr}$ intravenously. The details of this method are described elsewhere by Brookes (1965). To compare the red cell content of knee joint tissues,
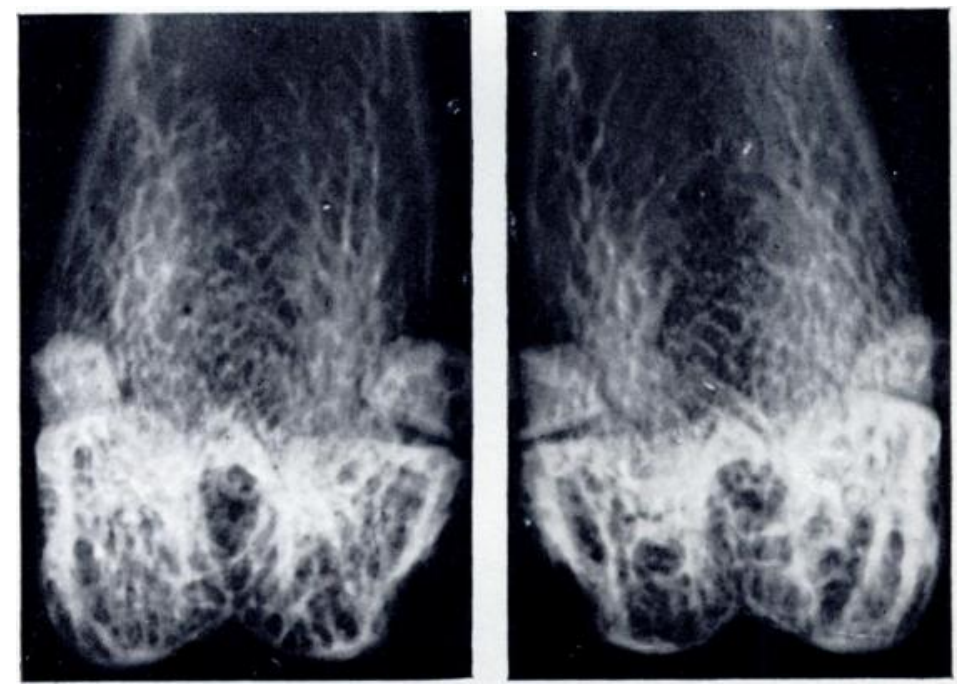

Fig. 3

Microradiograph of the inferior femoral epiphyses of a rat. $(\because 3 \cdot 7$.$) The$ left is normal. The right side has undergone eight weeks' venous engorgement and shows coarsening of trabeculation and increased radiodensity.

the radio-activities of congested tissue were calculated as a percentage of the contralateral control tissue.

The remaining rats in this experimental group were killed eight weeks after operation. The bones of some of the knee joints were cleaned of adherent soft tissues to eliminate errors due to non-bony shadows, and then radiographed. Other joints were fixed in formalin, decalcified and embedded in paraffin. Sections were cut at $7 \mu$ and stained with haematoxylin and eosin.

\section{RESULTS}

Ligation of the femoral and internal iliac veins ensured that the hind limb skeleton from the knee joint downwards underwent venous engorgement. This was demonstrated by the increased red cell content on the ligated side as compared with the contralateral control. (Femoral inferior epiphysis 136 per cent, tibial superior epiphysis 145 per cent).

The epiphyses in the congested knee joint eight weeks after operation showed radiographically a coarsening of epiphysial trabeculation (Fig. 3). Microscopically an increased 


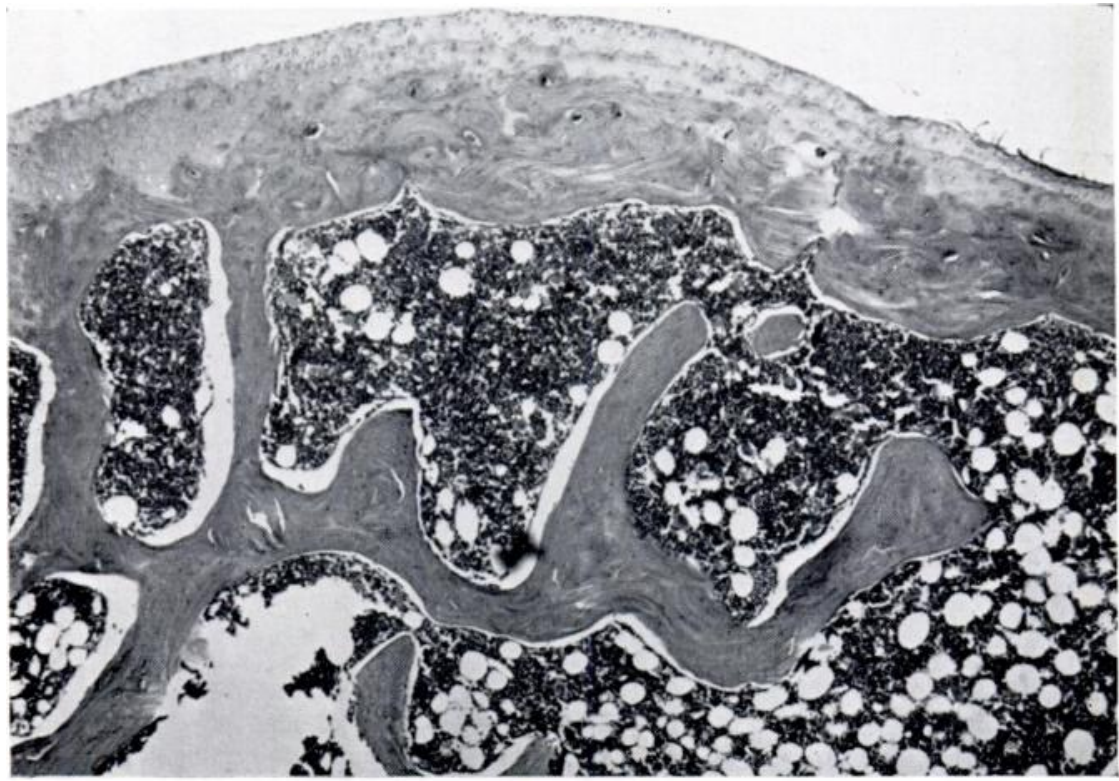

FIG. 4

Photomicrograph of the medial condyle of a normal rat femur. (Haematoxylin and eosin, $\times 65$.)

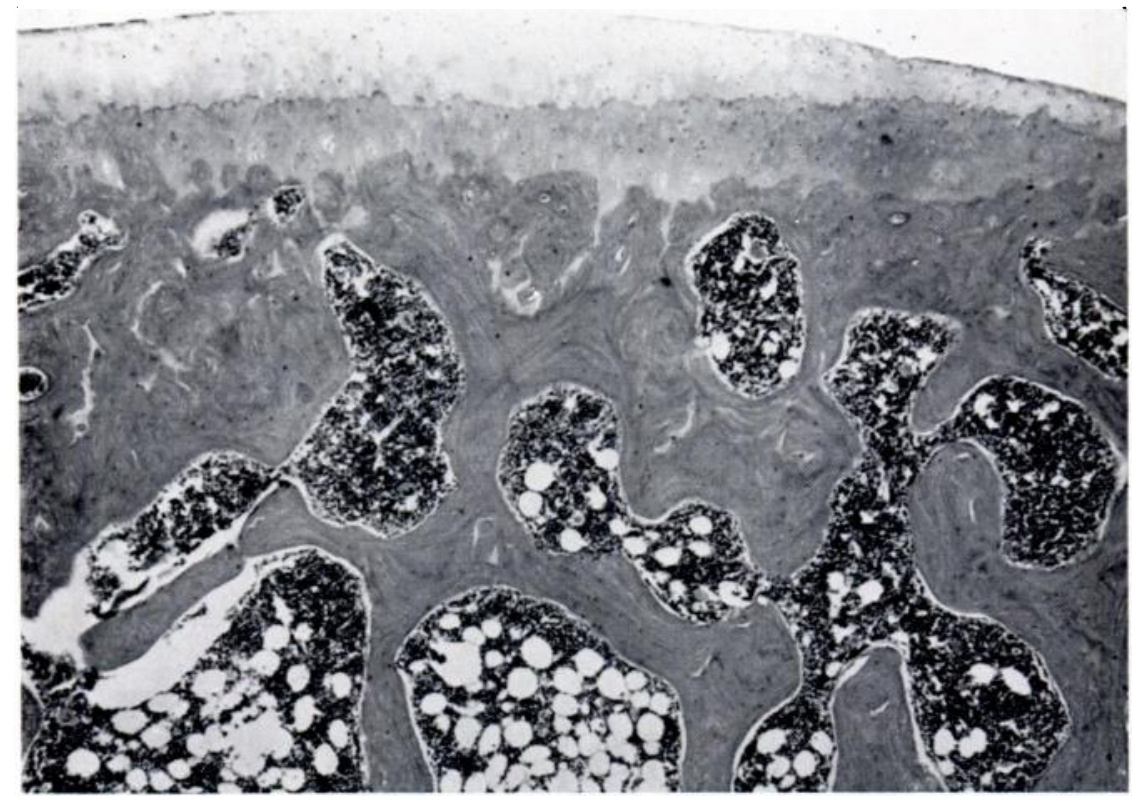

Fig. 5

Photomicrograph of the medial femoral condyle, from the side opposite to that shown in Figure 4, after eight weeks' venous engorgement. Increased thickness of bone trabeculae and of the calcified zone of cartilage are demonstrated. (Haematoxylin and eosin, $\times 65$.) 
amount of bone substance in tibial and femoral epiphyses was noted, evinced as a thicker subchondral bone plate and stouter trabeculation (Figs. 4 and 5). Comparison of matched sections of the knee joint epiphyses also indicated that the calcified zone of the articular cartilages, demarcated by a basophilic tide-line, was also increased in thickness (Figs. 6 and 7). During the short period of experimental venous congestion no other change in the light microscopical appearance of the joint cartilages was noted.

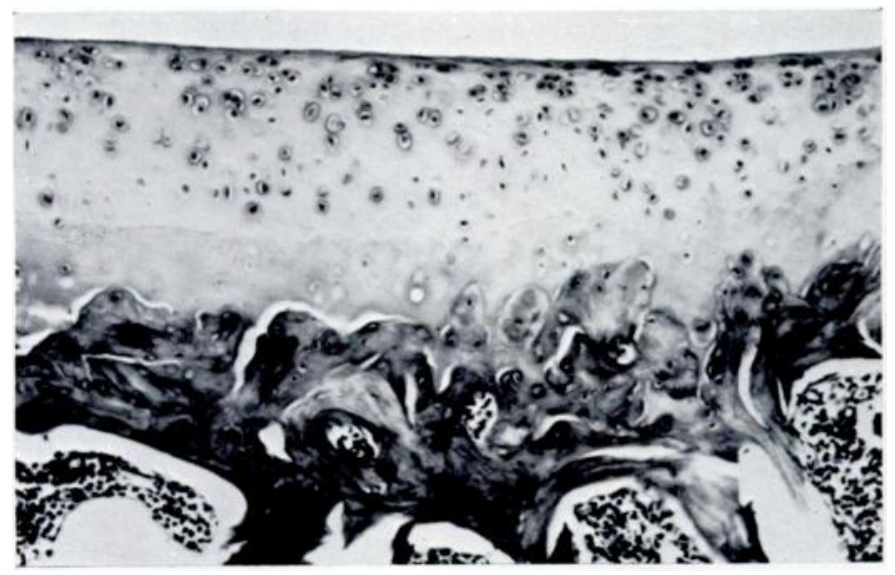

Fig. 6

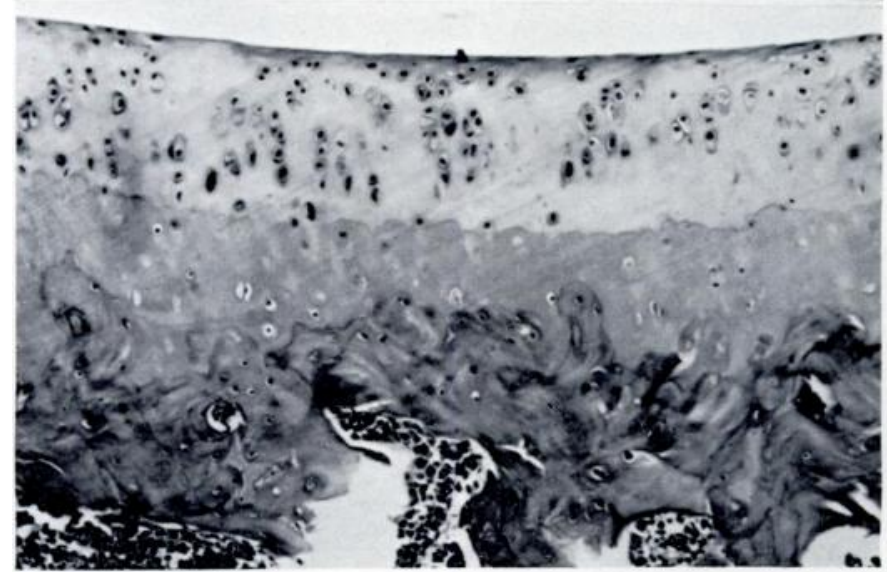

FIG. 7

Figure 6-Photomicrograph of a section through the joint cartilage of the medial tibial condyle of a rat, showing normal appearances. (Haematoxylin and eosin, $\times 96$.) Figure 7-Photomicrograph from the engorged side opposite to that shown in Figure 6 . The joint cartilage shows increased thickness of the zone of calcification. (Haematoxylin and eosin, $\times 96$.)

\section{EXPERIMENTAL FRACTURE REPAIR}

\section{MATERIALS AND METHODS}

Twelve rats, each weighing about 140 grammes (eight weeks old) were anaesthetised with ether. Both fibulae were fractured by snipping them through the midshaft with sharp-pointed scissors introduced through a lateral skin incision about 1 centimetre long. Healing in the control fracture was compared with the repair which took place in the presence of mild venous obstruction produced by femoral and internal iliac vein ligation carried out as already 
described. The rat fibula does not bear weight, and the tibia served as a natural splint during the process of repair. The rats were fully active after cessation of anaesthesia.

The lower limbs were radiographed at intervals of one week after operation. At two weeks and at four weeks, rats were killed. Some were perfused with indian ink injected into

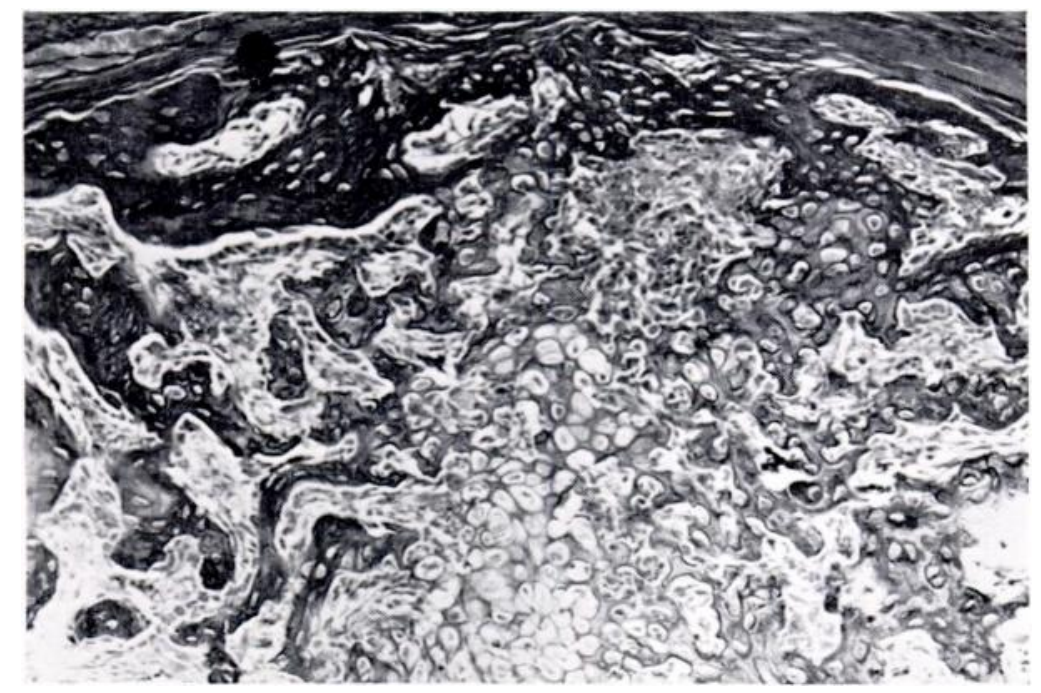

Fig. 8

Site of fibular fracture two weeks after operation showing normal cartilage bridging. (Mallory, 120.)

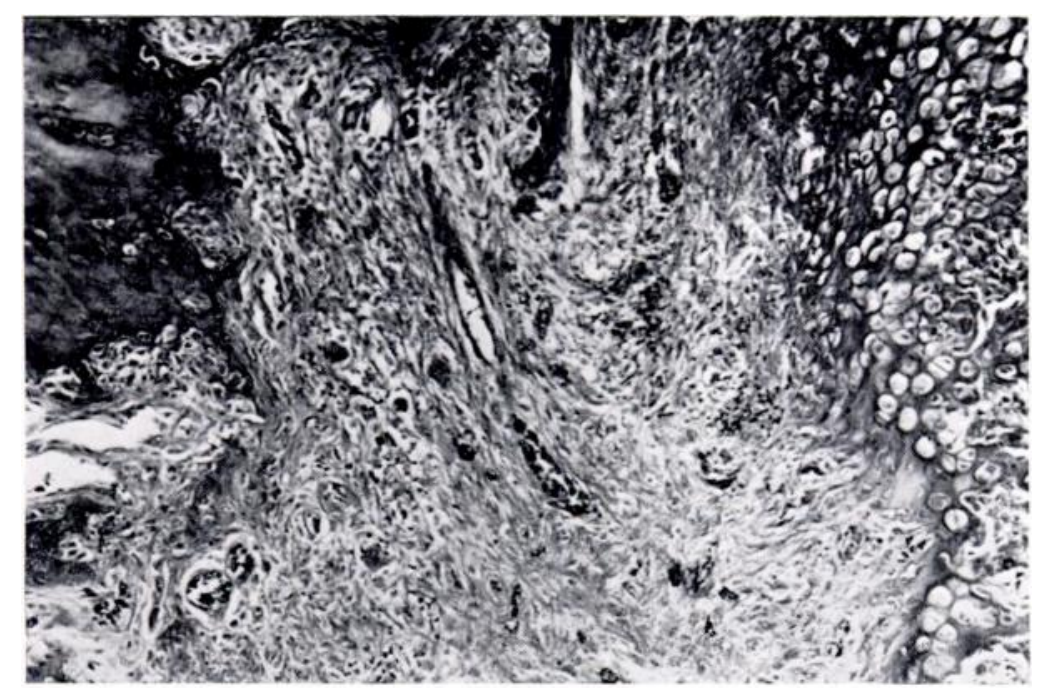

FIG. 9

Fracture site, from the side opposite to that shown in Figure 8, after two weeks' repair in an environment of venous engorgement. Profuse vascular blastemic tissue bridges the fragments. A little cartilage flanks the marrow cavity. (Mallory, $\times 120$.)

the heart. The hind limbs were removed, fixed in formalin, decalcified in 5 per cent nitric acid and embedded in celloidin. Sections through the fracture site were taken at $200 \mu$ and observed after clearing by the Spalteholz technique. In non-perfused rats the fibula was removed, fixed in formalin and processed in paraffin. Sections were cut at $7 \mu$ through the fracture site and stained with haematoxylin and eosin, Mallory’s trichrome stain, and with toluidine blue. 
RESULTS

One week after operation radiographic examination showed a fracture gap about a millimetre wide in the fibulae on both sides. The congested fracture, however, showed an increased amount of callus formation. At two weeks the difference in callus formation was marked, and microscopy of the normal fracture showed the gap was bridged by a plaque of cartilage reminiscent of a growth cartilage (Fig. 8). The congested fracture gap was largely filled with primitive, undifferentiated tissue which was bordered, however, by a thin strip of cartilage on either side which then gave way to an area of active bone formation (Fig. 9). Radiography also confirmed the more florid state of callus formation about the venously engorged fracture (Fig. 10). Cleared celloidin sections through the reparative areas revealed the profuse vascularity of the callus. The vessels were wider in calibre in those fractures where healing was taking place in the presence of venous ligations (Figs. 11 and 12).

After the fourth week after operation, osseous continuity had been established in both fibulae. The control fracture still showed a considerable quantity of excess bone in the marrow cavity. Fracture moulding was far from complete (Fig. 13). The engorged fibula on the other hand showed only minimal signs of the former presence of a fracture, indicated by a little excess subperiosteal and intramedullary bone (Fig. 14).

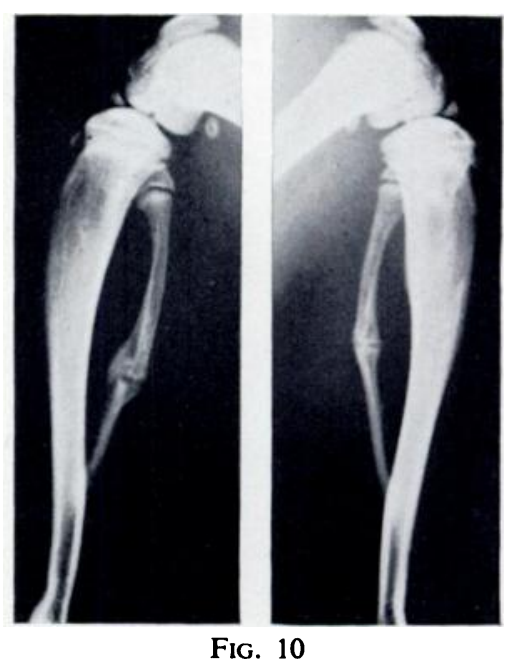

Radiograph of hind legs of a rat two weeks after production of bilateral fibular fractures. The left fracture is healing in the presence of venous engorgement and shows an increased production of callus. $(\because 2$.)

\section{REACTION OF THE BLOOD IN NORMAL BONE MATERIALS AND METHODS}

Under local anaesthesia, $0 \cdot 1$ millilitre samples of intraosseous blood were taken from the metaphyses and midshaft marrow of the femur and tibia in three-month-old rabbits. (Growth in length ceases at five months in these animals.) The gathering of samples was carried out by means of bore holes through which heparinised microhaematocrit tubes were inserted into cancellous areas or the marrow cavity proper. Blood specimens were introduced into a radiometer (Copenhagen) $\mathrm{pH}$ meter, which consists of a glass electrode balanced against a standardised calomel electrode at $\mathrm{pH} 7 \cdot 4$. The two are united by a capillary of blood whose $\mathrm{pH}$ it is desired to measure. Any deviation from $\mathrm{pH} 7 \cdot 4$ in the blood specimen sets up a potential difference between the glass and calomel electrodes which can be measured and calibrated in terms of $\mathrm{pH}$ of the blood sample to the second place of decimals at least.

RESULTS

Table I shows the values for the mean $\mathrm{pH}$ of blood samples taken from normal femoral and tibial sites in growing rabbits under ether anaesthesia. All $\mathrm{pH}$ values were on the alkaline side of neutrality. It is noted that the marrow values are more alkaline than the corresponding metaphysial ones. Furthermore, the knee joint metaphyses are more acid than metaphysial tissues in the neck of the femur or the lower end of the tibia. Hence, there seems to be no doubt that under these experimental conditions, the $\mathrm{pH}$ of the blood in the microcirculation showed an acid drift in those regions where bone formation is known to proceed at a higher rate.

\section{DISCUSSION}

The results of this investigation show that in clinical primary osteoarthritis, venous engorgement is present in the cancellous bone of the joint. Experimentally, there is an increased

VOL. 50 B, NO. 3, AUGUST 1968 


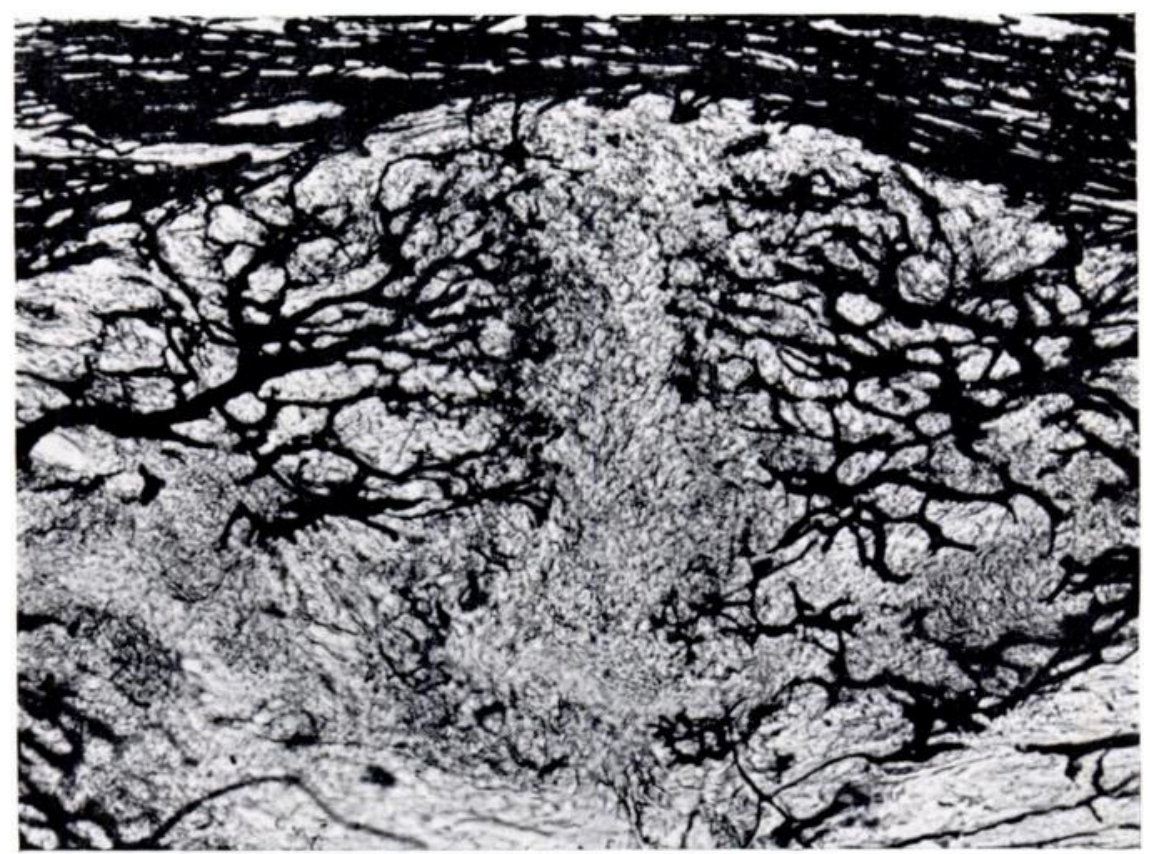

FIG. 11

Photomicrograph of cleared section through a normally healing fibular fracture in a rat two weeks after operation. (Indian ink perfusion, $\times 60$.)

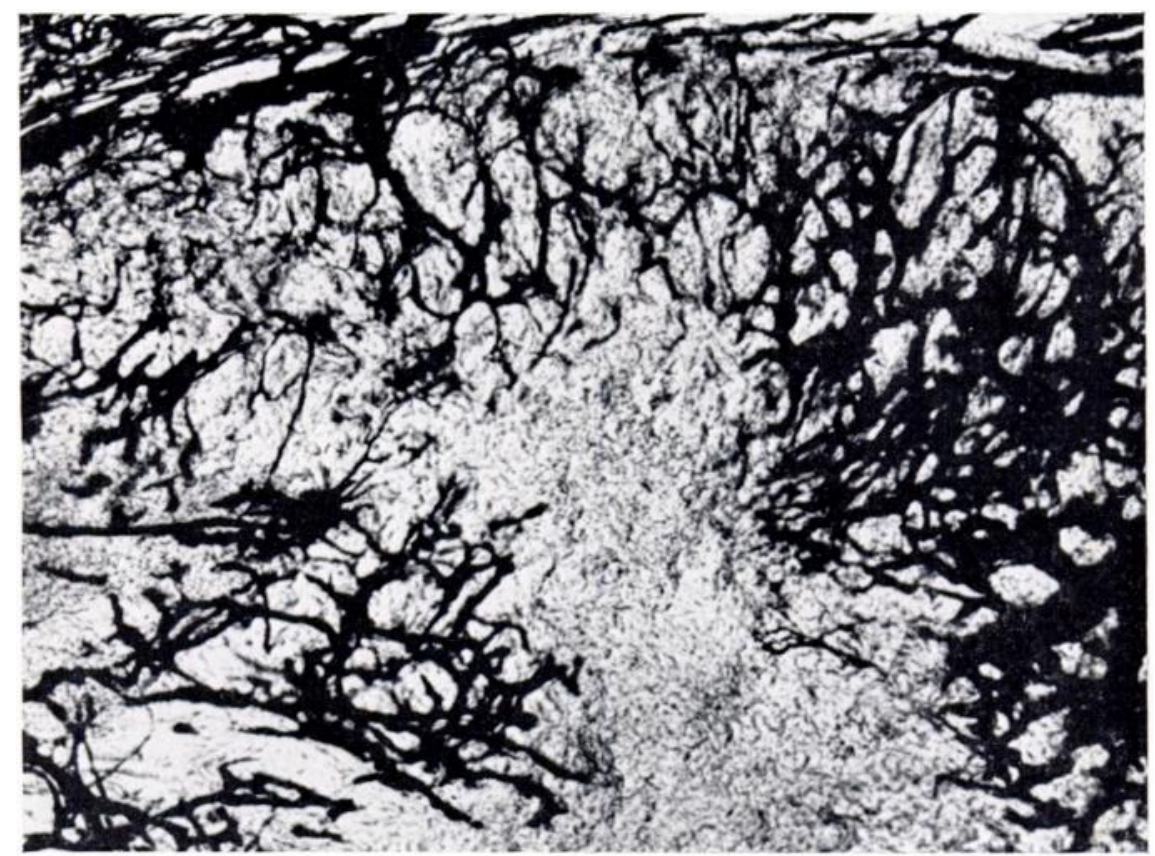

Fig. 12

Cleared section through an engorged fibular fracture in the opposite limb to that shown in Figure 11 two weeks after operation. Intense vascular congestion and sinusoid dilation is demonstrated. (Indian ink perfusion, $\times 60$.) 


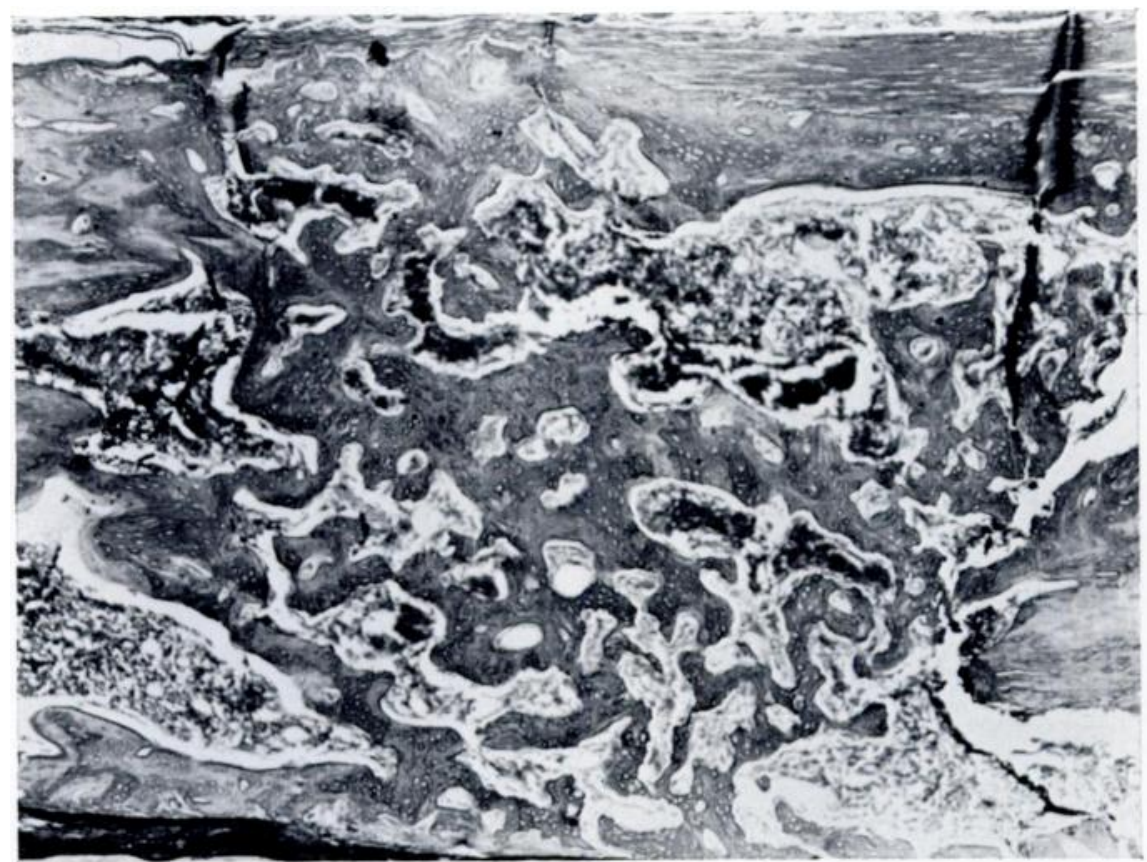

Fig. 13

Photomicrograph of a section through a fibular fracture after four weeks' repair in normal circumstances. A large plug of bone trabeculae fills the marrow cavity at the fracture site. (Mallory, $\times 135$.)

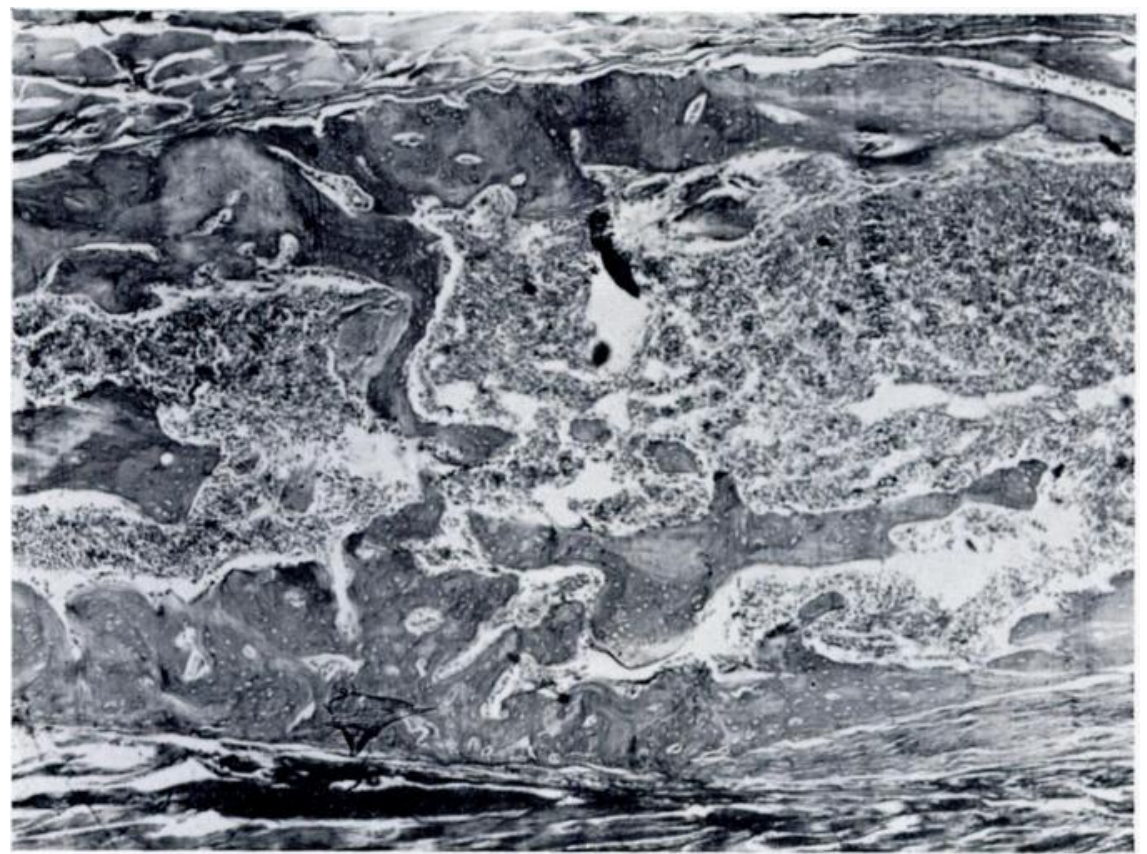

FIG. 14

Photomicrograph of a section through a fibular fracture in the opposite limb to that shown in Figure 13 after four weeks repair in the presence of venous engorgement. Bone restoration is virtually complete. (Mallory, $\times 60$.) 
joint trabeculation and calcification of articular cartilage in the presence of chronic venous congestion. Furthermore, experimental fracture repair was accelerated in the limb with venous congestion, and the production of cartilage which featured prominently in the normal, was almost abolished in the engorged fracture. Finally, in normal metaphysial tissues which are known to differ considerably in rates of bone formation, the more active site exhibits a microcirculation whose $\mathrm{pH}$ is more acid than that of the less active area.

TABLE I

Mean pH Values of the Blood in Various Parts of the Femur and TiBia

Figures obtained from observations on five normal rabbits

\begin{tabular}{|c|cc|}
\hline \multicolumn{1}{c}{} & Site of blood samples & pH \\
\hline \multirow{3}{*}{ Femur } & Superior metaphysis & $7 \cdot 34$ \\
& Marrow & $7 \cdot 40$ \\
& Inferior metaphysis & $7 \cdot 31$ \\
\hline \multirow{2}{*}{ Tibia } & Superior metaphysis & $7 \cdot 30$ \\
& Inferior metaphysis & $7 \cdot 37$ \\
\hline
\end{tabular}

That the venous ligation in the knee joint and fibular fracture experiments did in fact produce a circulatory impediment, is borne out by the increased red cell volumes in the knee joint and the dilation of the vessels in bone repair. How venous drainage of the congested limb takes place in the absence of large veins such as the femoral is not known for certain, but it is probable that the central venous sinus of the long bones in these circumstances assumes considerable importance, and conveys proximally a large quantity of venous blood which is shunted into them from the soft tissues of the limb (Brookes 1966). It is noted that Shaw (1966) found a rapid increase in the blood flow through the marrow of the femur after ligation of the femoral vein.

With regard to the knee joint experiments, venous engorgement would result in abnormality of the $\mathrm{pH}$ and the gas tensions of the circulation of the joint. There is evidence that as a result of such physicochemical changes the quality of the cartilage matrix that forms is also abnormal (Eichelberger 1960). Current opinion, however, favours the view that in primary osteoarthritis thickening of the bone plate is a result of abnormal forces consequent upon damage to the joint cartilage. From the evidence of our experiments it seems that, in the long term, a congested subchondral circulation exhibiting a reduced $\mathrm{pH}$ (that is, an increased hydrion concentration) and other physicochemical features characteristic of venous obstruction. initiates the formation of defective joint cartilage and also subchondral sclerosis. The latter may well be exacerbated by any mechanical derangements that are present. Nevertheless, it is suggested that subchondral venous congestion is an important causal factor in the genesis of the cartilage atrophy and joint eburnation seen in primary osteoarthritis.

As for the repair of fibular fractures observed in this investigation, essentially bone union and fracture moulding was accelerated in the presence of venous engorgement by the early production of an abundant young osteoblastic tissue, whereas relatively large amounts of bone accumulated in the neighbourhood of the normal site. The medullary bone trateculae had been entirely produced by the slow process of endochondral bone formation. Both the knee joint and fibular fracture experiments therefore indicate that in the presence of venous congestion the nett formation of bone is increased. It is interesting to note that many earlier workers have observed the same phenomenon (Pearse and Morton 1930, Bernstein 1933, Roome and McMaster 1934). On the other hand, Helal (1962) and Wardle (1964) have made 
explicit what is possibly representative of a considerable body of orthopaedic opinion, that the success of osteotomy in the treatment of osteoarthritis is due at least in part to the sustained venous decompression of the joint produced by this operation. In our view, the decompression slows down to normal proportions the nett formation of bone with the restoration of normal bone trabeculation.

The clinical demonstration of venous engorgement in the sclerotic bone of osteoarthritis given here and in other investigations (Pistolesi 1962, Wardle 1964, Helal 1965) together with the present experimental findings of increased bone formation resulting from venous congestion of a joint or of a healing fracture, suggest strongly that bone formation can be promoted by the physicochemical conditions characteristic of an impeded microcirculation. A reduced $\mathrm{pH}$ and $\mathrm{ppO}_{2}$ (partial pressure of oxygen), an increased $\mathrm{ppCO}_{2}$ and red cell content are but a few of the changes that may be expected in venous congestion. However, evidence about the $\mathrm{pH}$ and other physicochemical variables of blood taken from engorged bone is as yet not available. (Experiments to acquire this information are presently being conducted by us and an adequate body of results will shortly be published.) Nevertheless, as explained in the introduction to this paper, it is valid to examine the differences in normal bone production, because the movement of $\mathrm{pH}$ in conditions of excess bone production is thereby indicated. A drift towards acidity was observed here in normal cancellous metaphyses when compared with the intervening diaphysial marrow. It is arguable that the more marked acid drift in the "growing" as against the "non-growing" end of a bone is a result, rather than a cause, of increased osteogenesis. Nevertheless, the increased rate of bone formation in the normal bone continues to take place in an environment showing acid drift. It therefore seems very likely that, as a functional isolate, a raised hydrion concentration within physiological limits can increase the amount of bone formed in the growing end of a normal bone, or in the congested joints and fractures of these experiments, or in osteoarthritis.

The important blood factors, $\mathrm{ppO}_{2}$ and $\mathrm{ppCO}_{2}$ have not yet been measured in either the normal or osteoarthritic bone. From the work of Loomis (1961), the $\mathrm{ppCO}_{2}$ of an osteogenic tissue may act by stimulating cellular proliferation and osteoblastic differentiation, as occurred in the engorged fractures described here. A high red cell content might help to stabilise the $\mathrm{pH}$ of an engorged area which would otherwise become acid because of carbon dioxide retention (Brookes 1965). The role of oxygen tension in an osteogenic region, especially when considered together with the appropriate rate of blood flow (Brookes 1967), is very probably related to the total amount of bone turnover, because of the energy dependent nature of the protein synthesis involved in both bone formation and removal.

The present investigation, although originally stimulated by the unsolved problem of osteoarthritis, thus leads to a concept of control of osteogenesis in which the state of the microcirculation is given a central position. It is further postulated that sustained physicochemical changes in the microcirculation characteristic of venous engorgement can in abnormal circumstances initiate primary osteoarthritis. The nature of these abnormal circumstances are probably multifarious, but a fuller investigation than heretofore of the osseous circulation is urged as a first priority.

\section{SUMMARY}

1. The venographic findings in clinical primary osteoarthritis are described.

2. Experimental venous engorgement, of the knee joint and of healing fibular fractures, results in accelerated bone formation and disturbed cartilage formation.

3. Changes in $\mathrm{pH}, \mathrm{ppCO}_{2}$, and $\mathrm{ppO}_{2}$ are indicated as the chemical means by which chondrogenesis and osteogenesis can be altered.

4. It is suggested that chronic venous stress in joints is a causal factor in primary osteoarthritis.

VOL. 50 B, No. 3, AUgust 1968 
Our thanks are due to Professor Roger Warwick, Department of Anatomy, Guy's Hospital Medical School, for many helpful suggestions and useful advice, and to Mr W. A. Crabbe, Department of Orthopaedic Surgery, who has taken an active and stimulating interest in this work. Miss Susan Harman was responsible for the histological preparations, and Mr A. N. Finch gave valuable assistance with the photography. The research was supported financially by the Medical Research Council.

\section{REFERENCES}

Bernstein, M. A. (1933): Experimental Production of Arthritis by Artificially Produced Passive Congestion. Journal of Bone and Joint Surgery, 15, 661.

Brookes, M. (1965): Red Cell Volumes and Vascular Patterns in Long Bones. Acta Anatomica, $62,35$.

Brookes, M. (1966): The Vascular Factor in Osteoarthritis. Surgery, Gynecology and Obstetrics, 123, 1255.

Brookes, M. (1967): Blood Flow Rates in Compact and Cancellous Bone, and Bone Marrow. Journal of Anatomy, 101, 533.

Eichelberger, L. (1960): Hyaline Cartilage. Clinical Orthopaedics, 17, 77.

Harrison, M. H. M., Schajowicz, F., and Trueta, J. (1953): Osteoarthritis of the Hip: A Study of the Nature and Evolution of the Disease. Journal of Bone and Joint Surgery, 35-B, 598.

Helal, B. (1962): Osteoarthritis of the Knee. Thesis for M.Ch.(Orth.). University of Liverpool.

Helal, B. (1965): The Pain in Primary Osteoarthritis of the Knee. Postgraduate Medical Journal, $41,172$.

LoOmis, W. F. (1961): Cell Differentiation: A Problem in Selective Gene Activation. In Biological Structure and Function. Vol. 2, p. 501. Edited by T. W. Goodwin and O. Lindberg. London: Academic Press.

Pearse, H. E. Jun., and Morton, J. J. (1930): The Stimulation of Bone Growth by Venous Stasis. Journal of Bone and Joint Surgery, 12, 97.

Pistolesi, G. F. (1962): Il circolo venoso profondo dell'anca nell'artrosi. $9^{\circ}$ Rassegna internazionale del film scientifico-didattico. Produced by Istituto di Ortopedia e Traumatologia, Universitá di Padova, Italy.

Roome, N. W., and McMaster, P. E. (1934): Influence of Venous Stasis on Heterotopic Formation of Bone. Archives of Surgery, 29, 54.

Shaw, N. E. (1966): The Influence of Muscle Blood-flow on the Circulation in Bones. In Calcified Tissues 1965; Proceedings of the Third European Symposium on Calcified Tissues, p. 104. Edited by H. Fleisch, H. J. J. Blackwood and M. Owen. Berlin: Springer-Verlag.

Trueta, J. (1954): Osteoarthritis of the Hip. Annals of the Royal College of Surgeons of England, 15, 174.

WardLe, E. N. (1964): Osteotomy of the Tibia and Fibula in the Treatment of Chronic Osteoarthritis of the Knee. Postgraduate Medical Journal, 40, 536. 